\title{
Comportamento mecânico e estrutural de diferentes cortes cárneos em teste de determinação da força de cisalhamento
}

\author{
Mechanical and structural behaviours of different meat muscles in shear strength test
}

\author{
Lucas Arantes-Pereira ${ }^{1 *}$, Flávia Carolina Vargas' ${ }^{1}$, Paulo José do Amaral Sobral' \\ ${ }^{1}$ Universidade de São Paulo (USP), Faculdade de Zootecnia e Engenharia de Alimentos, Departamento de Engenharia de Alimentos, \\ Pirassununga/SP - Brasil
}

\begin{abstract}
*Corresponding Author
Lucas Arantes-Pereira, Universidade de São Paulo (USP), Faculdade de Zootecnia e Engenharia de Alimentos, Departamento de Engenharia de Alimentos, Campus da USP, Av. Duque de Caxias Norte, 225, CEP: 13635-900, Pirassununga/SP - Brasil, e-mail: lucas.arantes@usp.br
\end{abstract}

Cite as: Mechanical and structural behaviours of different meat muscles in shear strength test. Braz. J. Food Technol., v. 19, e2015076, 2016.

Received: Sept. 30, 2015; Accepted: June 23, 2016

\section{Resumo}

Neste trabalho, foram avaliados os comportamentos mecânico e estrutural de diferentes cortes cárneos em testes de determinação da força de cisalhamento, com o objetivo de identificar possíveis diferenças que podem interferir negativamente na mensuração da maciez objetiva. Seis cortes cárneos: Contrafilé (Longissimus dorsi), Maminha (Tensor fasciae latae), Lagarto (Semitendinosus), Filé-mignon (Psoas major) e Picanha (Biceps femoris) bovinos, e Lombo suíno (Longissimus dorsi) foram analisados de acordo com o método Warner-Bratzler, usando um texturômetro equipado com lâmina de $1 \mathrm{~mm}$ de espessura. As superfícies cisalhadas foram analisadas por microscopia eletrônica de varredura e as curvas mecânicas geradas durante os testes foram estudadas. Diferentes comportamentos foram observados nas curvas mecânicas e na microestrutura dos cortes cárneos em estudo. Alguns cortes apresentaram picos máximos bem definidos, enquanto outros apresentaram curvas mais abertas com maior distribuição da força durante os testes. Os cortes também apresentaram diferenças quanto à altura dos picos, que variou entre diferentes cortes e até em um mesmo corte. Nas microestruturas, foram observados diferentes comportamentos como: fibras deformadas por tracionamento, fibras aglomeradas devido a forte compressão e irregularidades na espessura e formato de fibras. Assim, concluiu-se que o teste de determinação da força de cisalhamento utilizado envolve outros princípios, como compressão e elongação, dependendo do corte cárneo estudado.

Palavras-chave: Maciez; Microestrutura; Compressão; Tracionamento.

\section{Summary}

This research evaluated the mechanical and structural behaviours of different meat cuts in shear force tests with the aim of identifying possible differences that could negatively influence objective tenderness measurements. Five Brazilian beef cuts (Longissimus dorsi, Tensor fasciae latae, Semitendinosus, Psoas major and Biceps femoris) and Pork loin (Longissimus dorsi)) were analyzed according to the Warner-Bratzler method using a texturometer equipped with a $1 \mathrm{~mm}$ thick blade. The sheared surfaces were analyzed by scanning electron microscopy and the mechanical curves generated during the tests were studied. Different behaviours were observed in the mechanical curves and in the microstructure of the meat cuts studied. Some muscles showed well defined maximum peaks while others showed wider curves with greater distribution of the force during testing. The muscles also varied with respect to peak heights between different muscles and even within the same muscle. Different behaviours were observed in the microstructure, such as fibers deformed by the tensile strength, agglomerated fibers due to the great compression and irregularities in fiber thickness and shape. Thus, it was concluded that the shear force test used involved other mechanical principles such as compression and elongation, depending on the meat cut studied.

Keywords: Tenderness; Microstructure; Compression; Tensile strength. 


\section{Introdução}

A maciez assume posição de destaque na matriz de qualidade da carne, sendo considerada como a característica sensorial de maior influência na aceitação por parte dos consumidores (JUÁREZ et al., 2012; KOOHMARAIE; GEESINK, 2006; VAN WEZEMAEL et al., 2014). Por este motivo, há muitos anos pesquisas têm sido desenvolvidas com o objetivo de melhor entender e medir a maciez de carnes (DERINGTON et al., 2011).

Um problema já identificado por pesquisadores da área é o fato de que, na maioria dos casos (Pesquisas e Indústria), apenas o músculo Longissimus é analisado quanto à maciez e, muitas vezes, é utilizado como indicador da qualidade de carcaças. Esta prática pode ser considerada como uma limitação tecnológica, uma vez que já foi demonstrado que há baixa associação entre os parâmetros de maciez sensorial e instrumental de diferentes músculos (HILDRUM et al., 2009), e que os efeitos de um tratamento tecnológico específico podem ser diferentes se aplicado em diferentes músculos (WHEELER et al., 1996). Dessa maneira, estudos que visem entender e melhor explicar essas divergências no comportamento de diferentes músculos, quando submetidos a tratamentos tecnológicos ou procedimentos analíticos, representam uma potencial solução para o aprimoramento do controle de qualidade da carne, em especial da maciez.

A avaliação instrumental pela mensuração da força de cisalhamento tem sido a principal ferramenta utilizada em estudos envolvendo a textura da carne (PINTO et al., 2010; HUIDOBRO et al., 2005). A força de cisalhamento é definida como a força que divide a amostra em partes contíguas por um deslizamento relativo de uma sobre a outra, numa direção paralela aos seus planos de contato, obtendo a separação da amostra quando se aplica força de corte ou uma mudança de posição (BOURNE, 2002). A ocorrência de outros princípios físicos durante a realização dos testes, de maneira isolada ou em concomitância com o cisalhamento, pode interferir negativamente nos resultados e, dependendo da intensidade, inviabilizar a realização do teste.

Alguns dos analisadores de textura modernos produzem uma curva mecânica de deformação, mostrando a força exercida ao longo do tempo ou distância percorrida pela lâmina durante o teste. O formato destas curvas pode ser utilizado como indicativo de outros parâmetros de qualidade (BOUTON et al., 1975; MØLLER, 1981; PIETRASIK et al., 2010; GIRARD et al., 2012) e, em tese, também revela o comportamento mecânico das amostras durante os testes, o que, por sua vez, estaria fortemente relacionado com a eficiência deles para utilização em diferentes músculos.

Considerando que a textura dos alimentos é derivada de sua estrutura (BOURNE, 2002), o estudo da microestrutura tem sido um pré-requisito necessário para entender e melhor descrever as propriedades de textura dos mais diversos tipos de alimentos, incluindo a carne e seus derivados. Técnicas de imagens têm sido bastante utilizadas em estudos envolvendo a microestrutura de alimentos, pois fornecem dados bastante significativos e eficientes (AGUILERA, 2005). Dessa maneira, a utilização da microscopia eletrônica de varredura para observação da microestrutura das superfícies rompidas pela lâmina durante o teste de determinação da força de cisalhamento representa uma possibilidade para melhor entender os efeitos deste teste, quando aplicado em diferentes músculos. Assim como as curvas mecânicas, a microestrutura das superfícies cisalhadas pode se tornar um indicativo da eficiência do teste.

Nessa premissa, o objetivo deste trabalho foi estudar os comportamentos mecânicos e estruturais de diferentes cortes cárneos em teste de determinação da força de cisalhamento, como forma de identificar possíveis diferenças que podem interferir negativamente nos resultados e também como possíveis novos métodos para avaliar a eficiência deste teste.

\section{Material e métodos}

O experimento foi conduzido na Faculdade de Zootecnia e Engenharia de Alimentos da Universidade de São Paulo (FZEA/USP) em Pirassununga SP. As amostras foram adquiridas em mercado consumidor local do município de Pirassununga e as análises foram realizadas no Laboratório de Tecnologia de Alimentos do Departamento de Engenharia de Alimentos.

\subsection{Amostras}

Foram utilizadas amostras de seis cortes cárneos comerciais, todas embaladas a vácuo e refrigeradas. Os cortes utilizados foram: Contrafilé (Longissimus dorsi), Maminha (Tensor fasciae latae), Lagarto (Semitendinosus), Filé-mignon (Psoas major) e Picanha (Biceps femoris) bovinos, e Lombo suíno (Longissimus dorsi). As amostras foram adquiridas no dia anterior ao da realização das análises e mantidas sob refrigeração a $4{ }^{\circ} \mathrm{C}$ até o momento de utilização. Foram adquiridas três peças inteiras de cada um dos cortes utilizados, de forma que cada peça foi utilizada como uma repetição do experimento.

\subsection{Preparo das amostras para os testes de cisalhamento}

As peças foram cortadas em bifes de 2,5 cm de espessura, no sentido perpendicular às fibras, colocadas individualmente em bandejas de alumínio e, posteriormente, assadas em forno elétrico (modelo Luxo 2.4 Classic, marca Layr) à temperatura de $170{ }^{\circ} \mathrm{C}$. A temperatura interna foi acompanhada com o auxílio de termômetros de perfuração 
(modelo Th1200C, marca Haenni). Quando atingiram a temperatura interna de $45^{\circ} \mathrm{C}$, os bifes foram virados e mantidos no forno até que a temperatura atingisse $70^{\circ} \mathrm{C}$. Depois de retiradas do forno, as amostras foram resfriadas em temperatura ambiente por quatro horas.

Subamostras cilíndricas foram retiradas no sentido paralelo às fibras da carne com o auxílio de um perfurador metálico de 1,27 cm de diâmetro interno para realização dos testes de determinação da força de cisalhamento, de acordo com as recomendações do protocolo padrão para o método Warner-Bratzler (AMSA, 2015).

Foi utilizado um bife de cada uma das peças dos cortes cárneos em estudo, sendo que, dos cortes que apresentam formato desuniforme ao longo da peça (Maminha, Filé mignon e Picanha), o bife foi extraído da porção que apresentou a maior área. De cada bife, foi extraído o máximo possível de subamostras cilíndricas, considerando a área útil do bife e a integridade das subamostras extraídas. O número total de subamostras extraídas de cada bife foi considerado como o número de replicatas, portanto o experimento foi realizado considerando três repetições e o máximo de replicatas possível para cada corte cárneo avaliado.

\subsection{Testes de determinação da força de cisalhamento}

As subamostras extraídas dos bifes foram submetidas a testes de determinação da força de cisalhamento, de acordo com o método Warner-Bratzler (AMSA, 2015), utilizando um Texturômetro (modelo TA.XT2i, marca Stable Micro Systems) equipado com uma lâmina padrão Warner-Bratzler com ângulo de corte com $60^{\circ}$ e espessura de 1,01 mm, conforme esquema apresentado na Figura 1.

Para a realização dos testes, as subamostras foram colocadas sobre um suporte, no centro da fenda por onde a lâmina se movimenta, e cisalhadas pela lâmina movendo-se à velocidade de $4 \mathrm{~mm} \cdot \mathrm{s}^{-1} \mathrm{em}$ direção descendente. O software do equipamento permite a leitura da força em tempo real, gerando assim uma curva mecânica de tensão ao longo do tempo. Tais curvas foram utilizadas para análise visual do comportamento mecânico dos cortes durante os testes.

A força de cisalhamento, expressa em $\mathrm{kg}$, foi determinada diretamente das curvas, como a força máxima exercida durante o teste, com o emprego do software Texture Expert v. 4.013.0 (Stable Micro Systems).

\subsection{Microestrutura dos cortes das amostras}

Depois da realização dos testes de cisalhamento, cinco metades das subamostras de cada corte foram escolhidas ao acaso, para estudo da microestrutura da superfície cisalhada. As metades de subamostras foram manipuladas o mínimo possível para evitar alterações na estrutura, o que poderia comprometer a visualização da estrutura original resultante do teste de cisalhamento, congeladas em freezer envolvidas em papel alumínio contendo pequenos furos, liofilizadas e mantidas em dessecador contendo sílica gel, para posterior análise. Um exemplo de metades de subamostras após a liofilização, imediatamente antes da análise no microscópio eletrônico de varredura, pode ser observado na Figura 2.

Foi utilizado um microscópio eletrônico de varredura (modelo TM-3000, marca Hitachi) com detector de elétrons retroespalhados, utilizando o modo de trabalho "Analy" que utiliza a maior voltagem de aceleração do equipamento (15 kV), porém trabalhando com a máxima tensão aplicada no canhão de elétrons, o que garantiu melhor resolução da imagem. O equipamento, além de operar em baixo vácuo, utiliza a tecnologia de pressão variável como modo de redução de carga ("charge-up reduction mode"), assim, o gás residual dentro da câmara minimiza

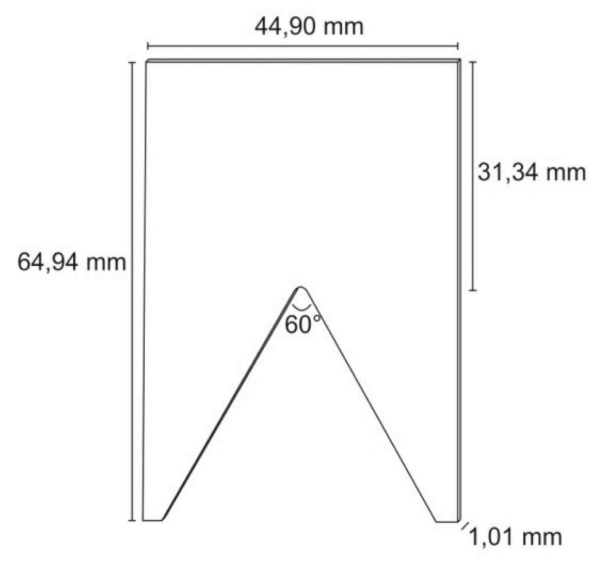

$17,0906 \mathrm{~g}$

Figura 1. Lâmina Warner-Bratzler "V" de 1 mm utilizada nas análises.

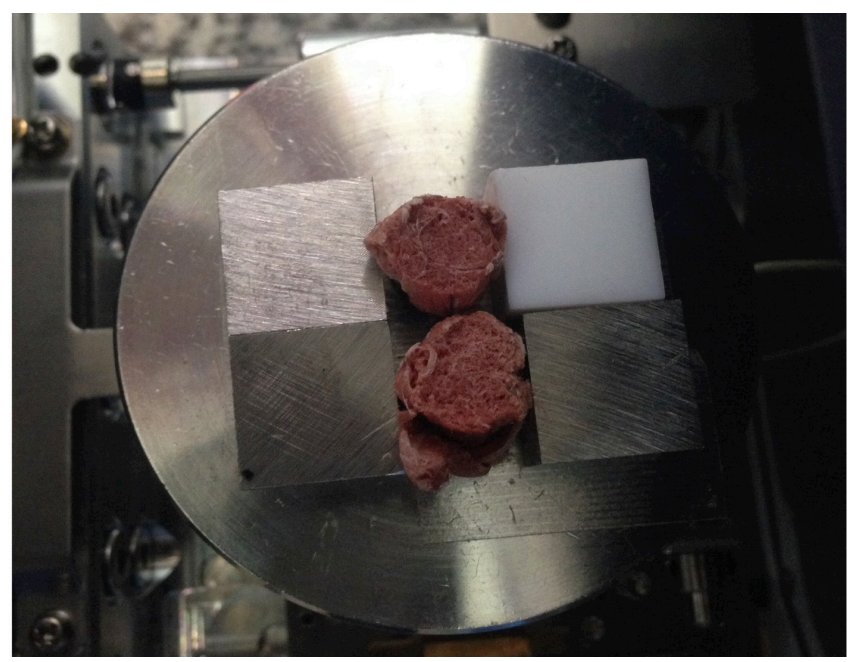

Figura 2. Metades de subamostras liofilizadas prontas para serem analisadas no microscópio eletrônico de varredura. 
as cargas superficiais de amostras não condutoras, o que, por sua vez, permitiu analisar as amostras de carne sem a necessidade de recobrimento metálico.

As imagens foram obtidas e tratadas utilizando o software Hitachi $3000^{\circledR}$ que acompanha o equipamento. Foram obtidas imagens de todas as cinco metades das subamostras de cada corte escolhidas ao acaso em diferentes magnitudes, sendo utilizado como critério de escolha das melhores imagens: a menor magnitude possível, visando observar uma maior superfície e, consequentemente, ter uma visão mais representativa da microestrutura dos cortes após o cisalhamento, e também as imagens que continham maior incidência de semelhanças na estrutura dentre as cinco amostras analisadas de cada corte. Para representação neste trabalho, foram escolhidas as imagens que melhor representavam a estrutura observada em cada um dos cortes em estudo.

\subsection{Análise estatística}

O experimento foi realizado em três repetições, ou seja, foram utilizadas três diferentes amostras de cada corte cárneo, sendo que cada uma destas amostras foi analisada no mínimo em triplicata, dependendo da área de cada bife e, consequentemente, do número máximo de subamostras extraídas de cada um. Foram realizadas análises estatísticas descritivas para as forças de cisalhamento, visando caracterizar a repetibilidade dos testes nos diferentes cortes cárneos avaliados. As análises foram realizadas por meio de procedimento PROC UNIVARIATE do programa Statistical Analysis System, versão 9.2 (SAS, 2004).

A análise do comportamento mecânico e estrutural dos cortes cárneos em estudo foi estritamente visual, por meio de observações e comparações no formato e amplitude das curvas mecânicas, bem como da composição e organização da microestrutura das superfícies cisalhadas.

\section{Resultados e discussão}

Os resultados da análise descritiva dos testes de determinação da força de cisalhamento dos cortes em estudo estão apresentados na Tabela 1.

Os cortes Filé-mignon e Picanha apresentaram as maiores médias de força de cisalhamento, ou seja, estes cortes foram considerados os de menor maciez, dentre os cortes avaliados. Por outro lado, é sabido que estes dois cortes são popularmente conhecidos por sua elevada maciez, o que sugere dizer que a determinação da força de cisalhamento utilizando o método Warner-Bratzler nas condições utilizadas neste estudo não é um bom indicativo da maciez para os cortes Filé-mignon e Picanha. Maiores valores de desvio padrão foram observados nos cortes Picanha e Lombo suíno, ou seja, houve maior variabilidade
Tabela 1. Análise descritiva dos resultados dos testes de determinação da força de cisalhamento dos cortes cárneos estudados.

\begin{tabular}{lccccc}
\multicolumn{1}{c}{ Corte } & $\mathbf{N}^{1}$ & $\begin{array}{c}\text { Média } \\
\mathbf{( k g )}\end{array}$ & $\mathbf{D . P}^{2}$ & $\begin{array}{c}\text { Valor } \\
\text { Mínimo } \\
\mathbf{( k g )}\end{array}$ & $\begin{array}{c}\text { Valor } \\
\text { Máximo } \\
\mathbf{( k g )}\end{array}$ \\
\hline Contrafilé & 19 & 4,6 & 1,1 & 2,5 & 6,9 \\
Maminha & 9 & 4,6 & 0,3 & 4,3 & 5,2 \\
Lagarto & 20 & 6,5 & 1,2 & 4,0 & 9,2 \\
Filé & 16 & 7,4 & 1,4 & 4,8 & 10,6 \\
mignon & 9 & 8,0 & 2,3 & 3,8 & 11,3 \\
Picanha & 9 & 5,4 & 2,2 & 3,2 & 10,4 \\
Lombo & 14 & 5,4 \\
suíno & & & & & \\
\hline
\end{tabular}

${ }^{1}$ Número total de subamostras cilíndricas analisadas, considerando as três repetições. ${ }^{2}$ Desvio Padrão.

nos resultados dos testes de determinação da força de cisalhamento destes cortes.

A provável hipótese para os altos valores de força de cisalhamento e desvio padrão dos cortes mencionados anteriormente é que existem fatores intrínsecos desses cortes que comprometem a boa performance do teste, tais como composição e estrutura química por exemplo. Porém, não foram encontrados na literatura, trabalhos que possam elucidar e melhor explicar estes comportamentos.

Na Figura 3, está apresentado o comportamento mecânico-estrutural do Contrafilé, composto pela micrografia da superfície cisalhada e as curvas mecânicas geradas durante os testes.

Observa-se que o teste de determinação da força de cisalhamento ocasionou rompimento com relevo irregular (A) das fibras em boa parte da superfície analisada, o que é característico do cisalhamento, porém também foi visível a presença de fibras deformadas por tracionamento (B) quando a amostra é rompida de forma brusca, descaracterizando o princípio de cisalhamento, pois, segundo Bourne (2002), quando uma amostra é cisalhada, percebe-se nítida separação da amostra, sem provocar deformação.

O comportamento mecânico do corte, observado nas curvas, foi parcialmente regular, ou seja, os maiores picos, tomados como as forças de cisalhamento, foram bem definidos e obtidos bem próximo aos 2 segundos de teste. Corroborando estas observações, o desvio padrão para este corte foi o segundo menor, demonstrando pequena variação nas forças de cisalhamento.

Para o corte Maminha, observou-se que o teste provocou rompimento bastante regular das fibras (Figura 4), ou seja, percebeu-se que as fibras apresentaram formas homogêneas, representando a seção transversal das fibras, o que é característico de aplicação do princípio de corte ao invés de cisalhamento (CHAIB, 1973). 

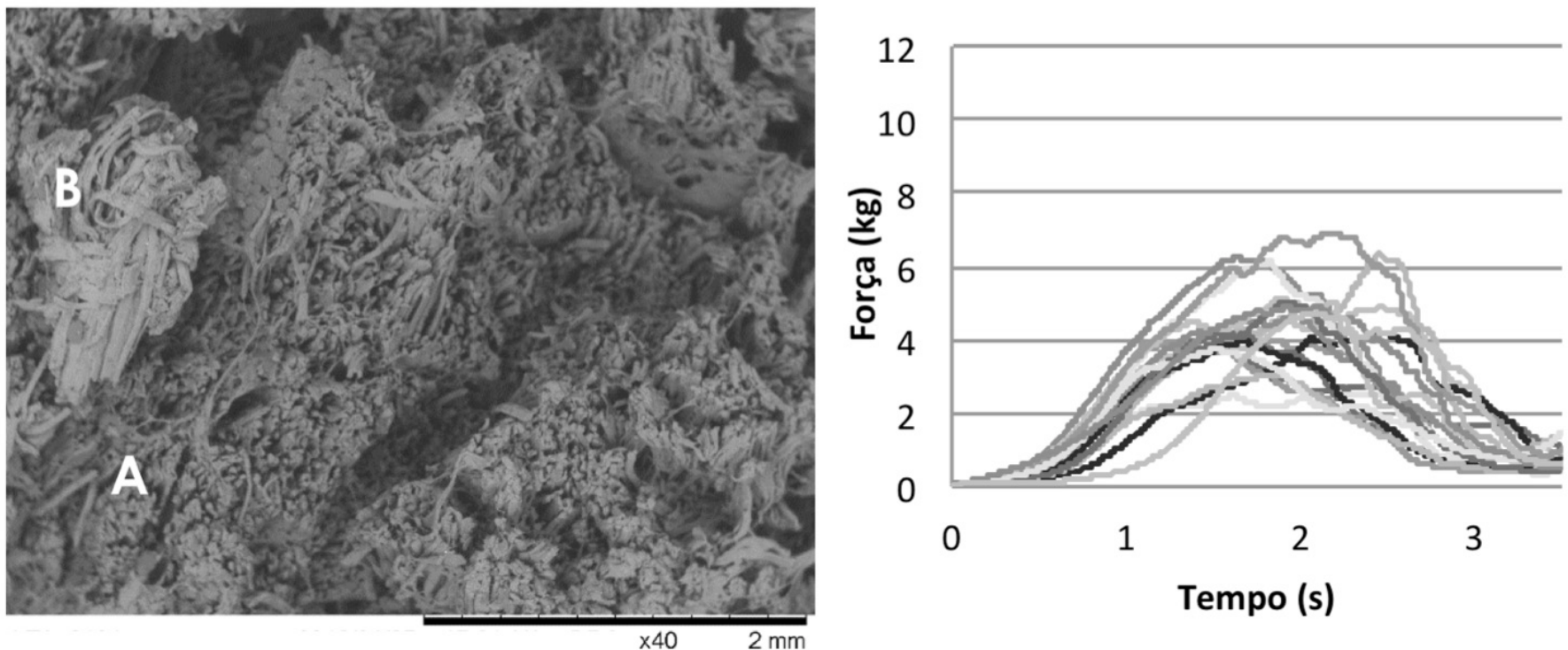

Figura 3. Comportamento mecânico-estrutural de Contrafilé (Longissimus dorsi) durante testes de determinação da força de cisalhamento. Esquerda: Micrografia da superfície cisalhada (Magnitude de 40x), onde: (A) Fibras onde ocorreu o princípio do cisalhamento; (B) Fibras deformadas por tracionamento; Direita: Curvas mecânicas geradas durante os testes.
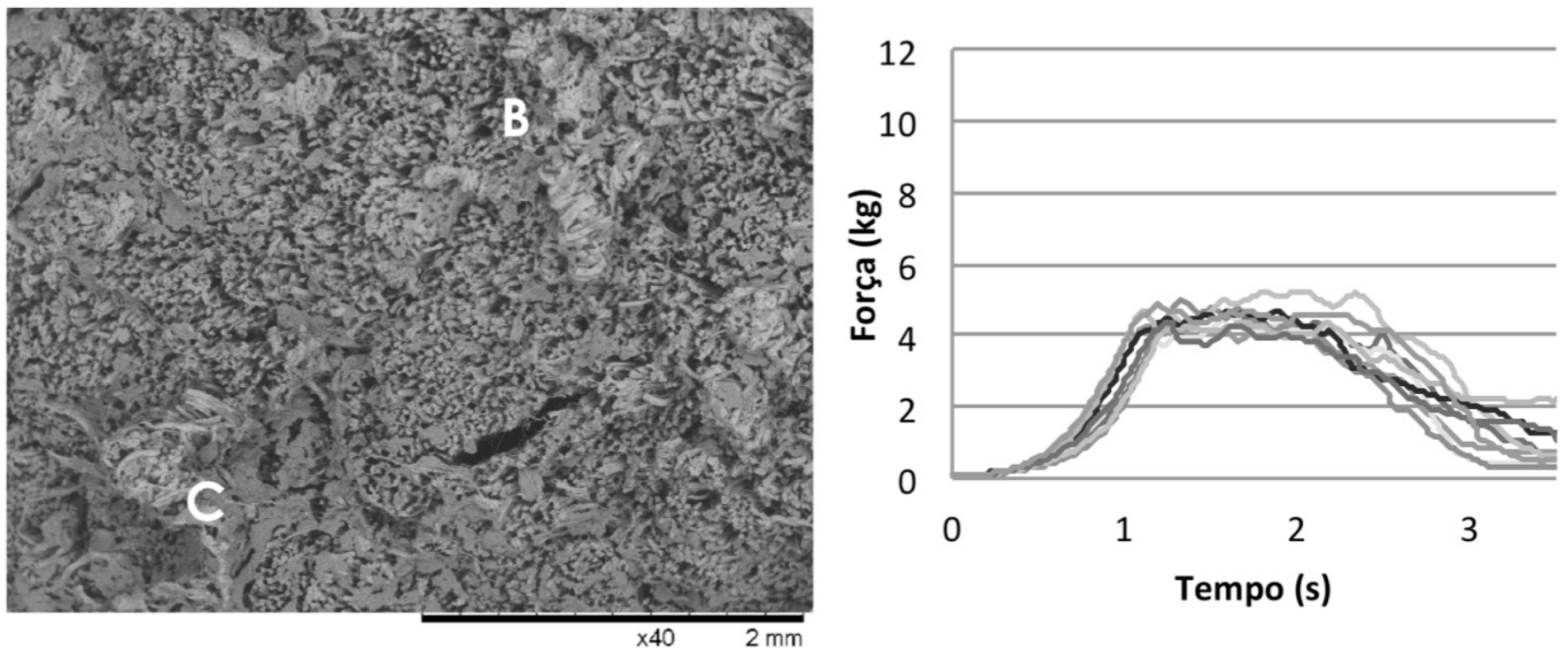

Figura 4. Comportamento mecânico-estrutural de Maminha (Tensor fasciae latae) durante testes de determinação da força de cisalhamento. Esquerda: Micrografia da superfície cisalhada (Magnitude de 40x), onde: (B) Fibras deformadas por tracionamento; (C) Fibras fortemente aderidas umas às outras, com formação de blocos; Direita: Curvas mecânicas geradas durante os testes.

Também foi observada uma aparente compressão da amostra, previamente ao cisalhamento, demonstrada pelo fato de que, em algumas regiões, as fibras ficaram aderidas umas às outras, formando espécies de blocos (C) e, ainda, a incidência de fibras deformadas por tracionamento $(\mathrm{B})$.

As curvas mecânicas geradas durante os testes demonstraram comportamento extremamente regular da Maminha. A força começou a ser exercida próximo a 0,5 segundo e uma sequência de pequenos picos ocorreu aproximadamente entre 1,1 e 2,1 segundos em todas as repetições, o que inclusive dificultou a observação do momento em que as forças de cisalhamento foram exercidas. Com base nestas observações e no baixo desvio padrão apresentado por este corte (Tabela 1), ficou evidente a ocorrência do princípio de corte ao invés de cisalhamento. 
Comportamento mecânico e estrutural de diferentes cortes cárneos em teste de determinação da força de cisalhamento Arantes-Pereira, L. et al.

O comportamento estrutural do Lagarto foi bastante heterogêneo, como pode ser observado na Figura 5. Grande incidência de fibras deformadas por tracionamento (B), fibras aderidas umas às outras e com relevo regular (C), demonstrando possível ocorrência de corte ao invés de cisalhamento, e maior incidência de espaços vazios (D) foram observadas. A maior incidência de espaços vazios pode ter sido causada por uma forte compressão da amostra, o que acarretou em um deslocamento das fibras.

Já o comportamento mecânico do corte, observado nas curvas, foi homogêneo. A força começou a ser exercida próximo a 0,5 segundo, seguindo-se aumento acentuado até próximo a 1,5 segundo e, em seguida, houve uma sequência de picos sugerindo o momento do rompimento das fibras. Houve maiores variações apenas na altura dos picos e, consequentemente, nos valores da força de cisalhamento, que, na maioria das repetições, ocorreu mais no final do teste, após os 2 segundos, e variaram de valores próximo a $4 \mathrm{~kg}$, até valores próximos a $9 \mathrm{~kg}$, o que reforça a possibilidade de ter ocorrido forte compressão das amostras antes do rompimento.

No Filé-mignon, foi observado comportamento estrutural bastante semelhante ao longo de toda a superfície analisada (Figura 6). Observou-se que houve rompimento
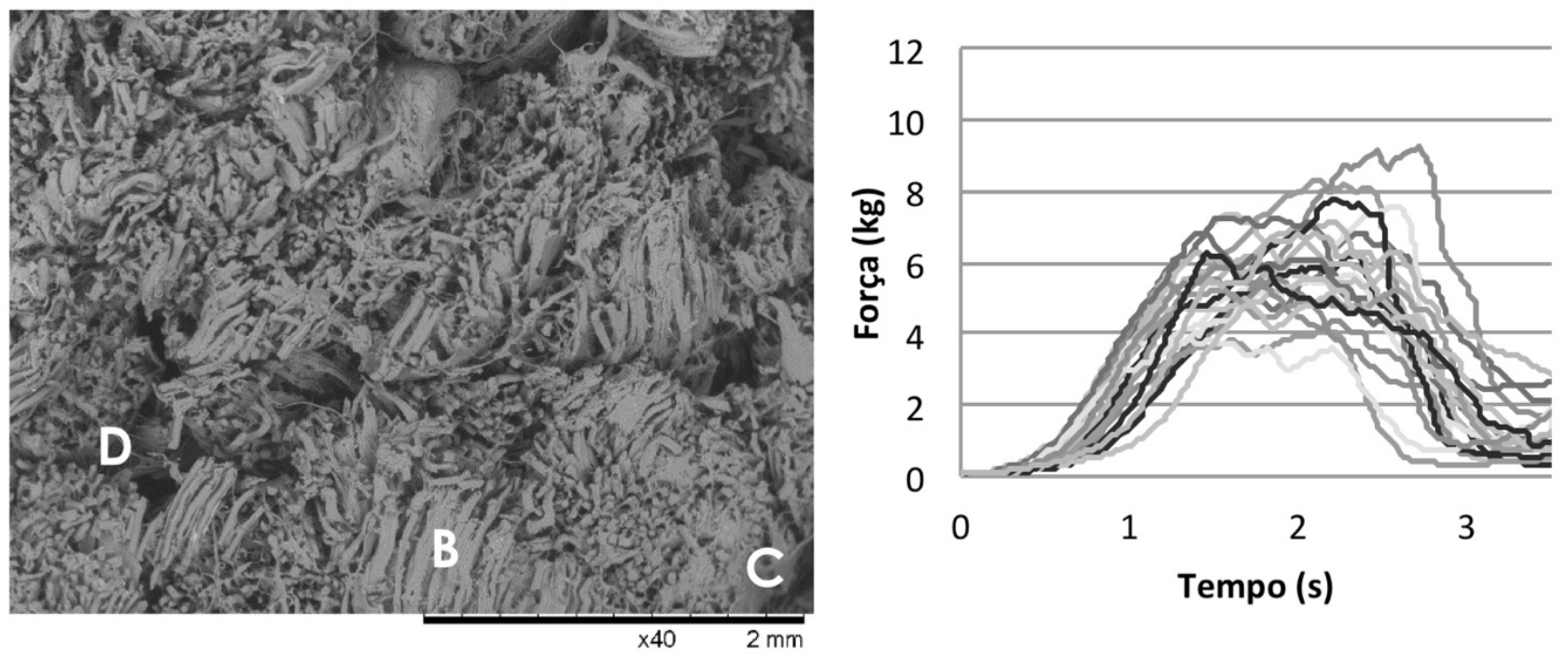

Figura 5. Comportamento mecânico-estrutural de Lagarto (Semitendinosus) durante testes de determinação da força de cisalhamento. Esquerda: Micrografia da superfície cisalhada (Magnitude de 40x), onde: (B) Fibras deformadas por tracionamento; (C) Fibras fortemente aderidas umas às outras, com formação de blocos; (D) Espaços vazios, sem incidência de tecidos; Direita: Curvas mecânicas geradas durante os testes.
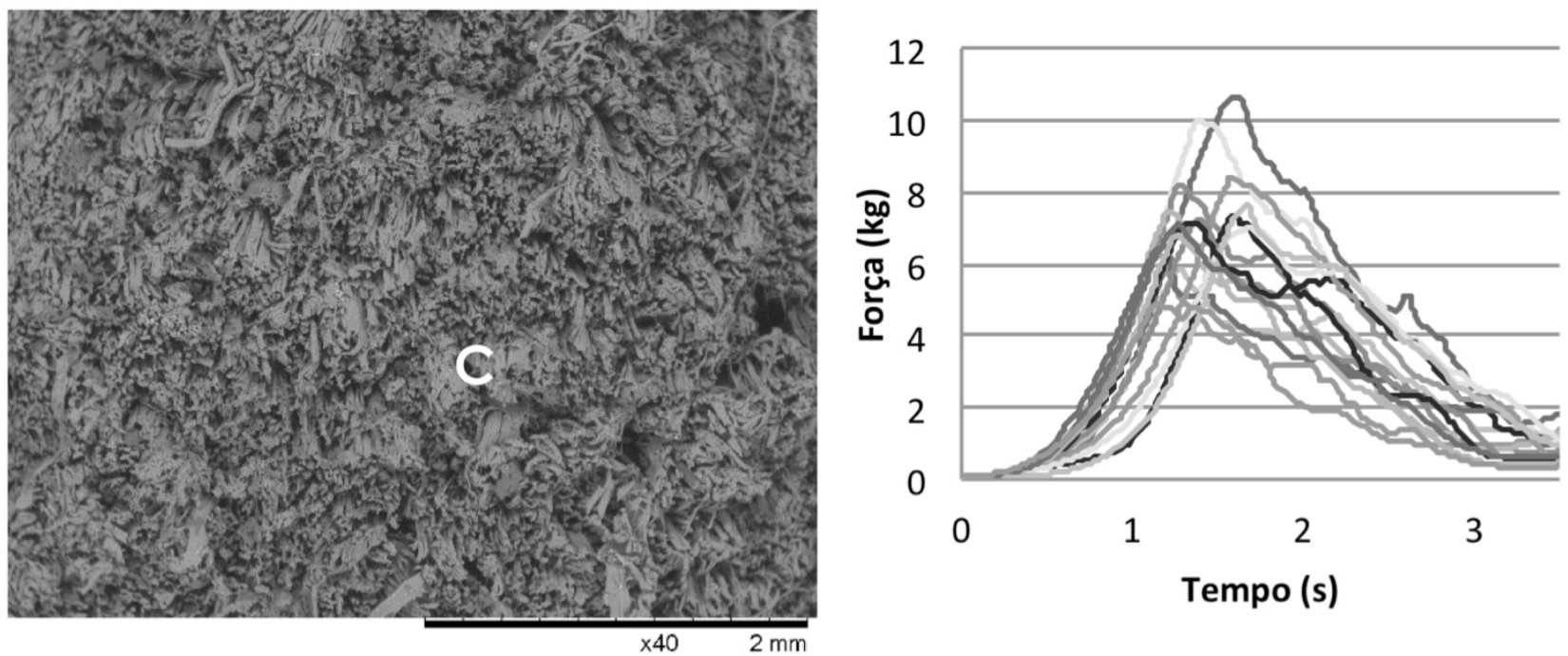

Figura 6. Comportamento mecânico-estrutural de Filé-mignon (Psoas major) durante testes de determinação da força de cisalhamento. Esquerda: Micrografia da superfície cisalhada (Magnitude de 40x), onde: (C) Fibras fortemente aderidas umas às outras, com formação de blocos; Direita: Curvas mecânicas geradas durante os testes. 
regular na maioria das fibras, o que sugere a ocorrência de corte ao invés de cisalhamento. Fibras aderidas umas às outras, formando pequenos blocos, ocorreram em algumas regiões da imagem $(\mathrm{C})$, indicando ocorrência de compressão. Além disso, é possível observar que grande parte das fibras está posicionada em direção à parte inferior da imagem, o que indica que, provavelmente, este foi o sentido percorrido pela lâmina, que, por sua vez, ocasionou leve tracionamento das fibras. Outra característica observada foi que, de maneira geral, as fibras deste corte, aparentemente são mais finas que as dos demais, o que certamente exerce influência no comportamento deste durante os testes.

Esta diferença na espessura das fibras do Filé-mignon corrobora as análises descritivas dos resultados dos testes de determinação da força de cisalhamento (Tabela 1), em que este corte inesperadamente apresentou a maior força de cisalhamento, validando a hipótese da interferência dos fatores intrínsecos dos cortes na performance dos testes.

O comportamento mecânico do Filé-mignon foi bastante diferente dos demais cortes em estudo. A principal diferença foi a ocorrência do maior pico logo no começo do teste, imediatamente após 1 segundo. Outra diferença observada foi que os picos foram bastante fechados e mais altos que a maioria dos demais cortes, ou seja, houve queda brusca da força aplicada, imediatamente após a ocorrência da maior força, o que, na maioria dos outros cortes, não ocorreu, além de valores mais elevados. Este comportamento demonstra a baixa eficiência da metodologia para este corte, uma vez que popularmente este músculo é considerado um dos mais macios da carcaça.

Assim como ocorrido com os demais cortes, os resultados dos testes com Picanha (Figura 7) evidenciaram a ocorrência de mais de um princípio físico envolvido. Observaram-se algumas fibras aparentemente cisalhadas (A), algumas deformadas por tracionamento (B) e ainda outras aderidas a outras, formando blocos (C). Além destas características, foi possível observar a ocorrência de um tecido diferente das fibras (E), aparentemente tecido conjuntivo deformado por tracionamento. Isto provavelmente pode ter sido causado por uma forte compressão da amostra, o que acarretou um deslocamento das fibras e consequente tracionamento do tecido.

O comportamento mecânico foi bastante heterogêneo principalmente quanto à altura dos picos, que está relacionada com a maior força necessária para o rompimento da amostra. Houve picos variando de valores próximos a $4 \mathrm{~kg}$ até valores próximos a $11 \mathrm{~kg}$. Além disto, observa-se também algumas variações no formato das curvas e no momento de ocorrência do maior pico, provavelmente devido a variações na composição deste corte. Estes comportamentos confirmam os resultados das análises descritivas da Tabela 1, na qual foram observados altos valores de força de cisalhamento e desvio padrão neste corte.

No comportamento estrutural do Lombo suíno (Figura 8), foi observada certa irregularidade na espessura e formato das fibras, muito possivelmente devido a uma forte compressão prévia ao cisalhamento. Praticamente
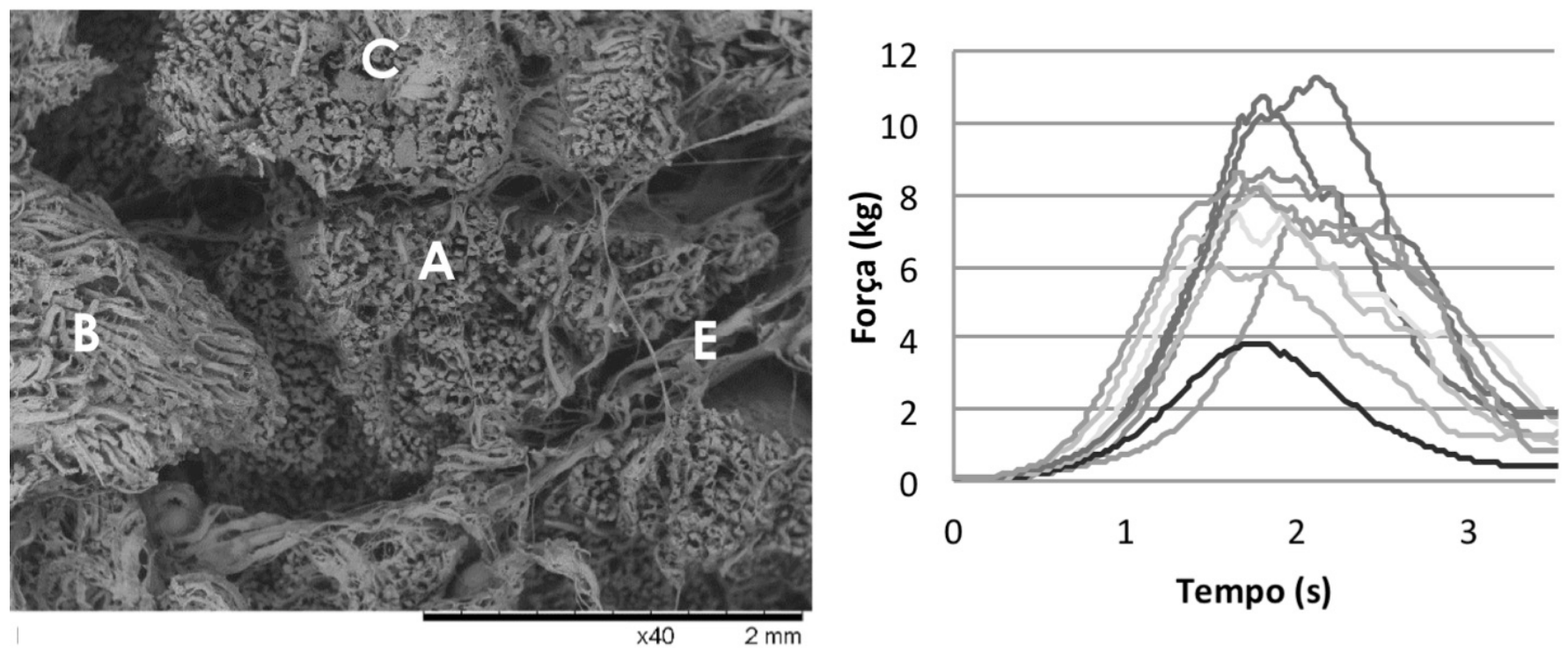

Figura 7. Comportamento mecânico-estrutural de Picanha (Biceps femoris) durante testes de determinação da força de cisalhamento. Esquerda: Micrografia da superfície cisalhada (Magnitude de 40x), onde: (A) Fibras onde ocorreu o princípio do cisalhamento; (B) Fibras deformadas por tracionamento; (C) Fibras fortemente aderidas umas às outras, com formação de blocos; (E) Tecido não fibrilar deformado por tracionamento; Direita: Curvas mecânicas geradas durante os testes. 

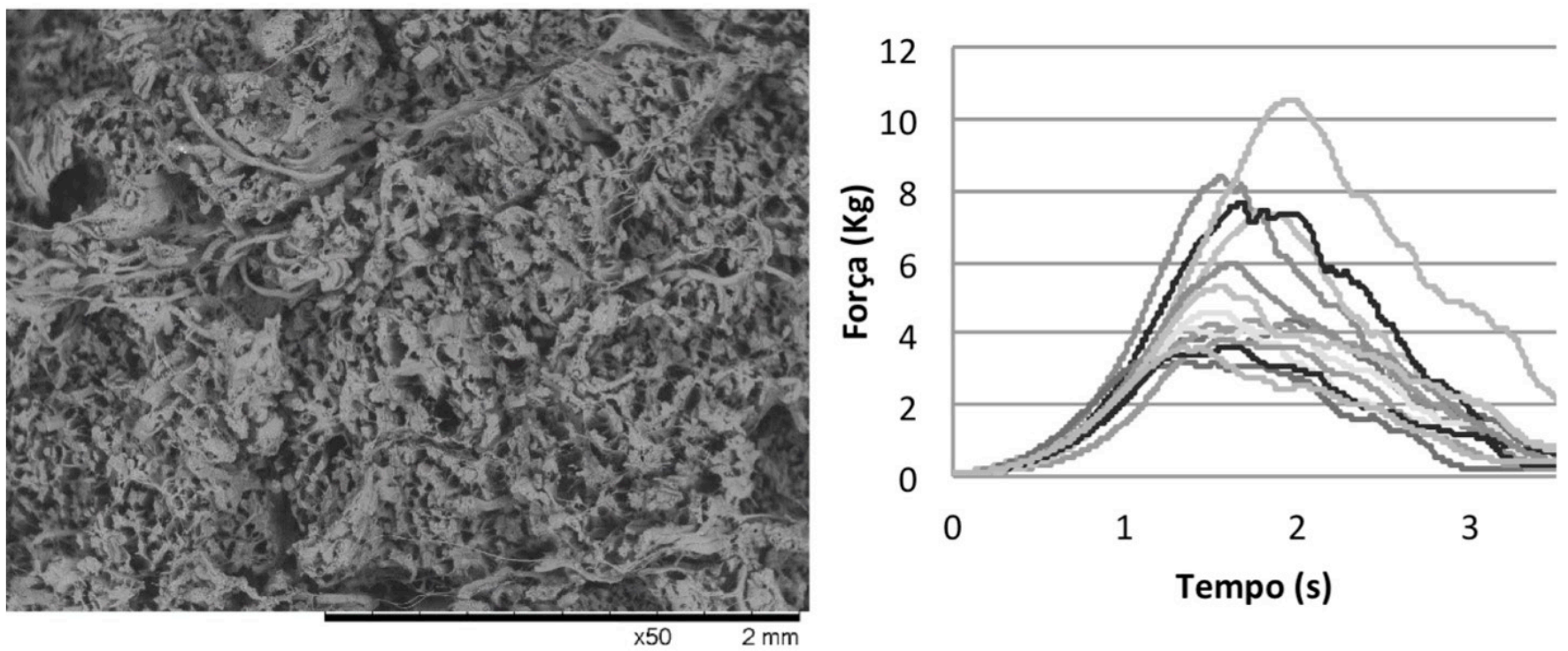

Figura 8. Comportamento mecânico-estrutural de Lombo suíno (Longissimus dorsi) durante testes de determinação da força de cisalhamento. Esquerda: Micrografia da superfície cisalhada (Magnitude de 50x); Direita: Curvas mecânicas geradas durante os testes.

não se observaram fibras isoladas, apenas em pequenos aglomerados. Consequentemente, observou-se a incidência de espaços vazios entre os aglomerados de fibras, também possivelmente devido à compressão.

O comportamento mecânico do Lombo suíno apresentou variações na altura dos picos e formato das curvas, similarmente ao ocorrido na Picanha. Porém, neste caso, as curvas ficaram divididas em dois grupos: um de curvas abertas, com distribuição mais uniforme da força ao longo do tempo de teste e baixas, quase todas por volta de $4 \mathrm{~kg}$ e outro de curvas mais fechadas e com picos altos e mais bem definidos, com altura máxima variando de valores próximos a $5 \mathrm{~kg}$ até valores acima de $10 \mathrm{~kg}$. A ocorrência deste comportamento confirma os resultados observados nas análises descritivas (Tabela 1), em que foi observado alto desvio padrão para o Lombo suíno, reforçando a hipótese de que alguns fatores intrínsecos dos cortes em estudo podem afetar a performance do teste de determinação da força de cisalhamento.

Com base nos resultados deste trabalho, é possível verificar que a determinação da maciez de diferentes cortes cárneos utilizando a força de cisalhamento ainda necessita de estudos e pesquisas. Isto porque, além das possíveis variações envolvidas durante os testes, a carne é um material bastante complexo que apresenta grandes variações na estrutura e composição (BOURNE, 2002; LAWRIE, 2005), o que, por sua vez, dificulta a padronização de uma metodologia única.

Além das variações na obtenção de resultados referentes à força de cisalhamento de carnes, observa-se que há uma grande dificuldade de correlacioná-los com a maciez subjetiva, principalmente para outros cortes além do Contrafilé. Corroborando esta afirmação, Hildrum et al. (2009), em estudo visando classificar diferentes músculos bovinos por meio das características sensoriais e da força de cisalhamento medida utilizando o método Warner-Bratzler, perceberam que, em alguns músculos, a maciez subjetiva apresenta resultados opostos à objetiva. Por exemplo, é possível observar que, na maciez sensorial, o músculo Biceps femoris apresentou valor bem abaixo do Longissimus dorsi, já, na avaliação utilizando Warner-Bratzler, o resultado foi o contrário, ou seja, o músculo apresentou resultado superior ao Longissimus dorsi, o que também ocorreu no presente trabalho. Além disso, os autores concluíram que o padrão de associação entre os músculos foi altamente irregular, o que significa que o uso do músculo Longissimus dorsi como um indicador de qualidade de todos os músculos na carcaça é questionável.

Outro fator que exerce grande influência na variação dos resultados de determinação da força de cisalhamento é a temperatura do tratamento térmico empregado no preparo das amostras. Souza (2008), ao comparar os efeitos da temperatura de cocção na força de cisalhamento medida utilizando o método Warner-Bratzler em Longissimus dorsi, verificou diferença significativa na maciez de bifes assados em temperaturas de 71 e $74{ }^{\circ} \mathrm{C}$. Com base nos resultados dessa autora, pode-se observar que uma pequena variação na temperatura já é suficiente para causar alterações nos resultados da maciez medida por métodos objetivos, e essas alterações provavelmente se dão em diferentes magnitudes, de acordo com o corte cárneo utilizado, o que deve ser levado em consideração em futuros estudos sobre o comportamento de cortes cárneos em testes de determinação da força de cisalhamento. 


\section{Conclusão}

O teste de determinação da força de cisalhamento utilizando Texturômetro equipado com lâmina de $1 \mathrm{~mm}$ de espessura provocou diferentes comportamentos na microestrutura e nas curvas mecânicas dos cortes cárneos estudados, uma vez que envolveu outros princípios físicos alheios ao cisalhamento, como compressão e elongação, dependendo do corte cárneo analisado. Com base nestas observações, foi possível verificar que há grande dificuldade em se realizar análises de mensuração da força de cisalhamento de diferentes cortes cárneos, sendo necessários mais estudos de otimização da técnica e correlação com a maciez sensorial.

A utilização de micrografias das superfícies cisalhadas e das curvas mecânicas geradas durante os testes de determinação da força de cisalhamento mostrou-se ferramenta eficiente no estudo do comportamento mecânico e estrutural dos cortes cárneos estudados, uma vez que ambos, em sua grande maioria, coincidiram e deram suporte aos resultados da análise estatística descritiva dos resultados. Sendo assim, esta abordagem representa um método promissor para a avaliação da eficiência e aprimoramento do método Warner-Bratzler.

\section{Referências}

AGUILERA, J. M. Why food microstructure? Journal of Food Engineering, Essex, v. 67, n. 1-2, p. 3-11, 2005. http://dx.doi. org/10.1016/j.jfoodeng.2004.05.050.

AMERICAN MEAT SCIENCE ASSOCIATION - AMSA. Research guidelines for cookery, sensory evaluation, and instrumental tenderness measurements of meat. 2. ed. Champaign: AMSA, 2015. (v. 1).

BOURNE, M. C. Food texture and viscosity: concept and measurement. 2. ed. San Diego: Academic Press, 2002. 423 p. http://dx.doi.org/10.1016/ B978-012119062-0/50001-2.

BOUTON, P. E.; HARRIS, P. V.; SHORTHOSE, W. R. Changes in shear parameters of meat associated with structural changes produced by aging, cooking and myofibrillar contraction. Journal of Food Science, Malden, v. 40, n. 6, p. 1122-1126, 1975. http://dx.doi. org/10.1111/j.1365-2621.1975.tb01032.x.

CHAIB, M. A. Métodos de avaliação de textura da carne. 1973. 98 f. Dissertação (Mestrado em Tecnologia de Alimentos)-Faculdade de Engenharia de Alimentos, Universidade Estadual de Campinas, Campinas, 1973.

DERINGTON, A. J.; BROOKS, J. C.; GARMYN, A. J.; THOMPSON, L. D.; WESTER, D. B.; MILLER, M. F. Relationships of slice shear force and Warner-Bratzler shear force of beef strip loin steaks as related to the tenderness gradient of the strip loin. Meat Science, Barking, v. 88, n. 1, p. 203-208, 2011. http://dx.doi.org/10.1016/j.meatsci.2010.12.030. PMid:21237578.

GIRARD, I.; BRUCE, H. L.; BASARAB, J. A.; LARSEN, I. L.; AALHUS, J. L. Contribution of myofibrillar and connective tissue components to the Warner-Bratzler shear force of cooked beef. Meat Science,
Barking, v. 92, n. 4, p. 775-782, 2012. http://dx.doi.org/10.1016/j. meatsci.2012.06.037. PMid:22842042.

HILDRUM, K. I.; RØDBOTTEN, R.; HØY, M.; BERG, J.; NARUM, B.; WOLD, J. P. Classification of different bovine muscles according to sensory characteristics and Warner Bratzler shear force. Meat Science, Barking, v. 83, n. 2, p. 302-307, 2009. http://dx.doi.org/10.1016/j. meatsci.2009.05.016. PMid:20416729.

HUIDOBRO, F. R.; MIGUEL, E.; BLÁZQUEZ, B.; ONEGA, E. A comparison between two methods (Warner-Bratzler and texture profile analysis) for testing either raw meat and cooked meat. Meat Science, Barking, v. 69, n. 3, p. 527-536, 2005. http://dx.doi.org/10.1016/j.meatsci.2004.09.008. JUÁREZ, M.; ALDAI, N.; LÓPEZ-CAMPOS, Ó.; DUGAN, M. E. R.; UTTARO, B.; AALHUS, J. L. Beef texture and juiciness. In: HUI, Y. H. (Ed.). Handbook of meat and processing. Boca Raton: CRC Press, 2012. cap. 9, p. 177-206.

KOOHMARAIE, M.; GEESINK, G. H. Contribution of postmortem muscle biochemistry to the delivery of consistent meat quality with particular focus on the calpain system. Meat Science, Barking, v. 74, n. 1, p. 34-43, 2006. http://dx.doi.org/10.1016/j.meatsci.2006.04.025. PMid:22062714.

LAWRIE, R. A. Ciência da carne. 6. ed. Porto Alegre: Artmed, 2005. $384 \mathrm{p}$.

MØLLER, A. J. Analysis of Warner-Bratzler shear pattern with regard to myofibrillar and connective tissue components of tenderness. Meat Science, Barking, v. 5, n. 4, p. 247-260, 1981. http://dx.doi. org/10.1016/0309-1740(81)90015-2. PMid:22056090.

PIETRASIK, Z.; AALHUS, J. L.; GIBSON, L. L.; SHAND, P. J. Influence of blade tenderization, moisture enhancement and pancreatin enzyme treatment on the processing characteristics and tenderness of beef semitendinosus muscle. Meat Science, Barking, v. 84, n. 3, p. 512-517, 2010. http://dx.doi.org/10.1016/j.meatsci.2009.10.006. PMid:20374818.

PINTO, M. F.; PONSANO, E. H. G.; ALMEIDA, A. P. S. Espessura da lâmina de cisalhamento na avaliação instrumental da textura da carne. Ciência Rural, Santa Maria, v. 40, n. 6, p. 1405-1410, 2010. http:// dx.doi.org/10.1590/S0103-84782010000600026.

SAS INSTITUTE INC. - SAS. Statistical analysis systems user's guide: $v$ 9.1.3. Cary, 2004. $846 \mathrm{p}$.

SOUZA, P. S. Comparação dos efeitos da temperatura de cocção e espessura da lâmina de corte na força máxima de cisalhamento Warner Bratzler, no Longissimus dorsi e, determinação de um modelo matemático que correlacione estes parâmetros com a força máxima de cisalhamen. PubVet, Maringá, v. 2, n. 7, 2008.

VAN WEZEMAEL, L.; DE SMET, S.; UELAND, Ø.; VERBEKE, W. Relationships between sensory evaluations of beef tenderness, shear force measurements and consumer characteristics. Meat Science, Barking, v. 97, n. 3, p. 310-315, 2014. http://dx.doi.org/10.1016/j. meatsci.2013.07.029. PMid:23962381.

WHEELER, T. L.; SHACKELFORD, S. D.; KOOHMARAIE, M. Sampling, cooking, and coring effects on Warner-Bratzler shear force values in beef. Journal of Animal Science, Champaign, v. 74, n. 7, p. 15531562, 1996. PMid:8818800. 